\title{
PATOGENIA DAS INFECÇÕES PELOS VÍRUS DO DENGUE
}

\author{
PATHOGENESIS OF DENGUE VIRUS INFECTIONS
}

Luiz Tadeu M. Figueiredo

\begin{abstract}
Docente do Departamento de Clínica Médica da Faculdade de Medicina de Ribeirão Preto da Universidade de São Paulo Correspondência: Prof.Dr. Luiz Tadeu M. Figueiredo - Unidade Multidepartamental de Pesquisa em Virologia da Faculdade de Medicina de Ribeirão Preto - Campus da USP - CEP: 14049-900 - Ribeirão Preto - SP - Brasil. E-mail: Itmfigue@fmrp.usp.br
\end{abstract}

FIGUEIREDO LTM. Patogenia das infecções pelos vírus do dengue. Medicina, Ribeirão Preto, 32: 15-20, jan./mar. 1999.

RESUMO: Neste trabalho de revisão, analisam-se aspectos das infecções primárias e secundárias pelos vírus do dengue, ressaltando a resposta imune benéfica, que impede a reinfecção e a resposta imune que facilita a entrada dos vírus do dengue em macrófagos e que é parte importante no mecanismo fisiopatológico do dengue hemorrágico. Esta forma de dengue é conseqüência de uma anômala resposta imune, envolvendo leucócitos, citocinas e imunocomplexos, causando aumento da permeabilidade por má função vascular endotelial, sem destruição do endotélio, com extravasamento de líquidos para o interstício, causando queda da pressão arterial e manifestações hemorrágicas, associadas a trombocitopenia.

UNITERMOS: Dengue; fisiopatologia. Vírus do Dengue.

Após serem inoculados através da picada do mosquito, os vírus do dengue fazem uma primeira replicação em células musculares estriadas, lisas e fibroblastos, bem como em linfonodos locais. Seguindo tal multiplicação, tem início viremia, disseminando-se por todo o organismo. Os vírus podem circular livres, no plasma ou no interior de monócitos/ macrófagos $^{(1)}$. Sabe-se que os vírus do dengue têm tropismo por essas células fagocitárias, as quais são os maiores sítios de replicação viral ${ }^{(2,3)}$.

Os sintomas gerais do dengue com febre e mal-estar surgem após período de incubação de dois (2) a sete (7) dias, coincidindo com a viremia. Esses sintomas relacionam-se a níveis séricos elevados de citocinas liberadas por macrófagos ao interagirem com linfócitos T (LT) helper ativados. Observam-se altos teores séricos de interleucina-2 (IL-2) e de seu receptor solúvel, de CD4 solúvel, interferon- $\gamma$ (IFN$\gamma$ ), interferon- $\alpha$ (IFN- $\alpha$ ) que se mantêm elevado até a convalescença, fator de necrose tumoral- $\alpha$ (TNF- $\alpha$ ), interleucina $1 \beta$ (IL-1 $\beta$ ) e o fator de ativação de pla- quetas (PAF). A leucopenia e a discreta e transitória depressão medular que se apresentam nesses casos, também, relacionam-se aos altos teores de citocinas macrofágicas. As mialgias são conseqüentes, em parte, à multiplicação viral no próprio tecido muscular e são acometidos, inclusive músculos oculomotores, sendo responsáveis pela cefaléia retroorbitária que muitos pacientes apresentam ${ }^{(1,2,3)}$.

A febre do dengue, nas formas indiferenciada e clássica é autolimitada e o desaparecimento da doença coincide com o aparecimento de vigorosa resposta imune $^{(1)}$. Os anticorpos, principalmente os que se ligam a epítopos da proteína $\mathrm{E}$, promovem lise do envelope ou bloqueio de seus receptores com conseqüente neutralização viral. A proteína $\mathrm{E}$, localizada nas espículas do envelope dos vírus do dengue, é fundamental para a ligação viral ao receptor de membrana e possui os mais importantes domínios antigênicos desses microorganismos. Os epítopos da proteína E definem a produção de anticorpos específicos para o tipo viral e para o gênero dengue e podem ser detectados 
por múltiplos testes sorológicos (ensaios imunoenzimáticos e de imunofluorescência; testes de neutralização, de inibição da hemaglutinação e de facilitação da infectividade) ${ }^{(4)}$. A estrutura tridimensional da proteína E consiste de um complexo dimérico com duas subunidades idênticas. Eé subdividida em três regiões distintas: I, região central da molécula, contendo o radical amina terminal; II, contém a maior parte dos contatos do dímero; III, inclui o $\mathrm{C}$ terminal e tem relação com a virulência de determinadas cepas virais. Os dímeros da proteína $\mathrm{E}$, quando expostos a pH ácido ( $\mathrm{pH}<6,5)$, sofrem uma transformação conformacional, sendo rearranjados em trímeros. Após a ligação viral ao receptor de membrana e a entrada da partícula no citoplasma por pinocitose, a conformação em trímeros da proteína E seria fundamental para o processo de fusão do envelope viral com a membrana endossômica. Os anticorpos contra a proteína E são dirigidos a epítopos existentes em toda a superfície externa da molécula. Os anticorpos neutralizantes relacionam-se à específica conformação do epítopo da proteína E nas regiões I e II para um determinado vírus. O mecanismo de neutralização relaciona-se à dissociação do dímero $\mathrm{E}$ pela presença do anticorpo, impedindo as alterações conformacionais que levam à formação dos trímeros da molécula. A neutralização também pode ocorrer com anticorpos ligados à região III, obstruindo o sítio de ligação viral ao receptor de membrana celular ${ }^{(2,4,5,6)}$.

Anticorpos, produzidos contra NS1, promovem lise viral fixando o complemento. A NS1, com $40 \mathrm{KDa}$, possui atividade na maturação viral e é encontrada na superfície, ligada à membrana da célula infectada sendo, também, secretada ${ }^{(2)}$. A imunização com NS1 é capaz de proteger camundongos da encefalite, após serem inoculados com vírus do dengue ${ }^{(7)}$. Entretanto, o mecanismo de proteção conferido pelas NS1 não é neutralizante das partículas virais e relaciona-se à destruição das células infectadas previamente à liberação da progênie viral ${ }^{(2)}$. Anticorpos contra NS1 atuam como mediadores de fenômenos de citotoxidade por linfócitos, através de seus receptores para a porção Fc de imunoglobulinas. A NS3, que se apresenta em contato com a superfície celular ou é secretada, também, possui capacidade imunogênica. Essa proteína, com $69 \mathrm{KDa}$, é uma enzima bifuncional nucleotídea trifosfatase/helicase viral. A presença de NS3 estimula a destruição das células infectadas por LT citóxicos. LT helper e citotóxicos de pacientes com dengue apresentam capacidade de reconhecer epítopos de $\mathrm{E}, \mathrm{NS} 1$ e $\mathrm{NS} 3^{(2,8)}$.
Nos pacientes com dengue, a resposta humoral, produzida por plasmócitos resultantes da ativação de linfócitos B costuma ser vigorosa. Os anticorpos IgM específicos são detectáveis a partir do quarto $\left(4^{\circ}\right)$ dia, após o início dos sintomas, atingindo os níveis mais elevados por volta do sétimo $\left(7^{\circ}\right)$ ou oitavo $\left(8^{\circ}\right)$ dia e declinando lentamente, passando a não ser detectáveis após alguns meses. As IgG específicas são observadas, em níveis baixos, a partir do quarto $\left(4^{\circ}\right)$ dia após o início dos sintomas, elevam-se gradualmente, atingindo altos teores em duas (2) semanas e mantêm-se detectáveis por vários anos, conferindo imunidade contra o tipo infectante, provavelmente, por toda a vida $^{(9)}$. Anticorpos obtidos durante infecção por um tipo de dengue, também, protegem da infecção por outros tipos, entretanto, tal imunidade é mais curta, com duração de meses ou poucos anos. Infecções por dengue, em indivíduos que já tiveram contato com outros sorotipos do vírus ou, mesmo, outros Flavivirus (como os vacinados contra a febre amarela), podem alterar o perfil da resposta imune, que passa a ser do tipo anamnéstico ou de infecção secundária (reinfecção), com baixa produção de IgM e liberação intensa e precoce de $\operatorname{IgG}^{(10)}$.

A resposta imune celular citotóxica por LT ocorre sob estímulo das proteínas NS1, NS3 e E dos vírus do dengue ${ }^{(2,5)}$. LT helper atuam na presença das células infectadas com dengue que expressam receptores HLA tipo II, produzindo IFN $\gamma$, IL-2 e o fator estimulador de colônias de macrófagos e granulócitos. Os linfócitos citotóxicos agridem diretamente as células infectadas com dengue, que expressam receptores HLA tipo I, lisando-as ${ }^{(11)}$. Portanto, as células T participam ativamente na resposta imune, reduzindo o número de células infectadas com o vírus, e conferindo proteção contra reinfecção.

A segunda forma de resposta imune aos vírus do dengue é paradoxal, ou seja, prejudica o hospedeiro infectado e é responsável pela imunopatologia do dengue hemorrágico/síndrome de choque do dengue (dengue hemorrhagic fever/dengue shock syndro$m e-\mathrm{DHF} / \mathrm{DSS})$. Essa resposta imune pode ser observada em dois (2) grupos de indivíduos: acima de um (1) ano de idade com uma segunda infecção por dengue (mais de $90 \%$ dos casos) e crianças, menores de um (1) ano, infectadas pela primeira vez, filhos de mães possuídoras de anticorpos para dengue ${ }^{(2,11)}$.

DHF/DSS é comum em países do Sudeste Asiático e Oceano Pacífico Ocidental, onde a virose ocor- 
re endemicamente, com circulação simultânea de mais de um tipo viral. Naqueles locais, a doença acomete, mais comumente, crianças. No Brasil, atualmente, vive-se a mesma situação com a circulação simultânea dos vírus dengue tipo 1 e 2. Entretanto, em surtos de DHF/DSS ocorridos nas Américas e, particularmente, no Brasil, os doentes são, predominantemente, indivíduos adultos de ambos os sexos ${ }^{(12 / 17)}$.

Uma seqüência de infecções por dengue foi claramente definida como importante fator de risco para DHF/DSS ${ }^{(12)}$. Em epidemias ocorridas no Sudeste Asiático e Ilhas do Oceano Pacífico, observou-se que pacientes com DHF/DSS sofreram, com maior freqüência, infecção inicial por dengue tipo 1,3 ou 4, seguida, após intervalo de um (1) a cinco (5) anos, de infecção por dengue tipo 2. Em 1981, na epidemia de DHF/DSS, ocorrida em Cuba, isolou-se de pacientes o tipo 2, quatro (4) anos após a ocorrência de uma epidemia benigna pelo tipo $1^{(13)}$. Na ocasião, determinou-se que o risco de DHF/DSS, em infecção secundária, seria aproximadamente cem (100) vezes maior do que em uma primoinfecção. A importância de uma infecção secundária ou terciária por dengue, aumentando o risco de DHF/DSS, foi corroborada em estudo mais recente, efetuado em Myanmar ${ }^{(14)}$.

Observa-se que, nos casos de infecção seqüencial por dengue apresentando DHF/DSS, os anticorpos preexistentes, obtidos quando da infecção prévia por outro tipo viral, não neutralizam o segundo vírus infectante de tipo diferente e amplificam a infecção, facilitando ao novo tipo infectante a penetração em macrófagos. Os vírus utilizam a porção Fc dos anticorpos ligados ao envelope para a ligação com os receptores de membrana Fc $\gamma$, presentes na membrana celular macrofágica ${ }^{(18)}$. Trata-se do fenômeno de facilitação por anticorpos da penetração viral em macrófagos (antibody dependent enhancement - ADE). $O$ segundo grupo de pacientes de risco para DHF/DSS são lactentes que receberam, intra-útero, anticorpos maternos contra dengue. Com o passar de meses, tais anticorpos, que apresentam queda paulatina, atingem níveis subneutralizantes. No caso de infecção desses lactentes pelo mesmo tipo de dengue que causou a infecção materna e, na presença dos anticorpos subneutralizantes, ocorreria $\mathrm{ADE}$, e os pacientes desenvolveriam DHF/DSS ${ }^{(19)}$.

Na fisiopatologia do DHF/DSS, agrava o ADE, estímulo de IFN $\gamma$, liberado por LT helper ativados, causando uma aumentada exposição de receptores Fc $\gamma$ em membrana dos macrófagos, tornando-os mais permissíveis ao vírus ${ }^{(20)}$. Acredita-se que indivíduos com DHF/DSS possuam populações de macrófagos maciçamente infectadas e produzam viremias elevadas. A presença aumentada de moléculas HLA classes I e II, nos macrófagos apresentando antígenos, facilita o reconhecimento de múltiplos epítopos virais pelos LT helper e citotóxicos ${ }^{(2,20)}$.

Os antígenos de dengue, expressos na membrana macrofágica induzem fenômenos de eliminação imune por LT helper e citotóxicos. Os macrófagos, ativados pelos linfócitos e agredidos ou lisados pelas células citotóxicas, liberam tromboplastina, iniciando fenômenos da coagulação e proteases ativadoras do complemento, causadoras de lise celular e de choque ${ }^{(11)}$. O TNF- $\alpha$, de origem macrofágica e linfocitária, encontra-se em níveis séricos elevados, em casos graves de DHF/DSS, afetando células inflamatórias e endoteliais, contribuindo para a trombocitopenia, induzindo IL-8, estimulando liberação de histamina pelos basófilos e aumentando a permeabilidade vascular ${ }^{(2,21)}$. A IL-6 sérica elevada, observada em alguns casos graves de DHF/DSS, provavelmente, induz a hipertermia apresentada por esses pacientes. Também, anafilotoxinas, como $\mathrm{C}_{3 \mathrm{a}}$ e $\mathrm{C}_{5 \mathrm{a}}$, leucotrienos, histamina e o fator inibidor do ativador do plasminogênio (impede a fibrinólise e leva à deposição de fibrina intravascular) encontram-se presentes, por curto tempo, no DHF/DSS ${ }^{(11)}$.

Estudos mostram altos teores séricos de moléculas CD4 e CD8 solúveis em casos de DHF/DSS sugerindo a ativação de linfócitos $\mathrm{T}^{(20)}$. Nesses mesmos estudos detectaram-se altos níveis de IFN- $\gamma$, IL-2, TNF- $\alpha$. Na infecção secundária por dengue, epítopos de células T, particularmente os de proteínas NS, podem ser reconhecidos de forma cruzada entre os vírus e influiriam na agressão macrofágica. A IL-2 conseqüente à ativação de LT estimula extravasamento capilar e ativação de complemento. A agressão pelos LT citotóxicos ativados sobre os macrófagos infectados com dengue, é reconhecida. Também, um fator citotóxico, induzido pelos vírus do dengue, com $43 \mathrm{KD}$, liberado por LT helper foi descrito inicialmente, em camundongos. Animais inoculados com este fator simulavam o quadro apresentado por pacientes de dengue hemorrágico, com extravasamento de líquidos do intravascular para o interstício. Trata-se de uma citocina com características distintas das outras conhecidas até então, que age sobre células liberadoras de histamina e mata seletivamente algumas células T, macrófagos e megacariócitos. Seu me- 
canismo de ação é dependente de cálcio e relacionase à produção de nitritos e de oxigênio. Sob efeito do fator citotóxico, células desenvolvem apoptose, ocorre liberação de histamina com aumento da permeabilidade vascular e alterações hematológicas. Fator citotóxico similar ao de camundongos já foi encontrado em seres humanos a partir de células mononucleares ativadas do sangue periférico. $O$ fator citotóxico humano, também, causa efeito dose-dependente similar ao de camundongo. Este efeito pode ser bloqueado com anticorpos específicos contra o fator e anti-histamínicos, abrindo futuras perspectivas terapêuticas para o DHF/DSS ${ }^{(11,22,23)}$.

Recentemente, foram descritos, em pacientes com dengue, anticorpos de reação cruzada entre um epítopo da proteína $\mathrm{E}$ e o plasminogênio. A importância desses anticorpos, causando uma eventual perturbação da fibrinólise e interferindo nos fenômenos hemorrágicos relacionados à doença, ainda precisa ser melhor avaliada $^{(22)}$.

Fatores próprios do hospedeiro, também, têm papel reconhecido no desenvolvimento de DHF/DSS. Na epidemia cubana de dengue hemorrágico, em 1981, observou-se o maior número de casos em brancos e relacionou-se ainda a anemia falciforme, diabetes melitus e asma brônquica como fatores de risco ${ }^{(13)}$. Também, fatores genéticos como o haplotipo HLA relacionam-se à gravidade dos $\operatorname{casos}^{(11)}$.

Finalmente, não apenas a resposta imune e as características próprias do indivíduo infectado estariam associadas aos quadros graves de dengue. A cepa de dengue infectante, nos casos de infecção secundária, é reconhecida como provável fator determinante para o aparecimento do dengue hemorrágico e sabe-se que DHF/DSS ocorre em freqüência desproporcionalmente mais alta, quando a infecção é causada pelo tipo $2^{(24)}$. Também, observa-se nessas epidemias de dengue, agravamento clínico dos casos com a progressão do surto, sugerindo um aumento da virulência do microorganismo após passagens sucessivas em seres humanos ${ }^{(6)}$. É provável que variações na virulência de distintas cepas virais possam contribuir para a gravidade de infecções por dengue. Evidência disso foi o aparecimento do DHF/DSS nas Américas, apenas após a introdução, nessa parte do mundo, de variantes específicas do sorotipo 2, originárias do $\mathrm{Su}-$ deste Asiático ${ }^{(24)}$. Pesquisadores, utilizando anticorpos monoclonais para dengue tipo 4 , observaram boa correlação entre variações antigênicas em diferentes cepas de vírus tipo 2 e facilitação da infecção macrofágica pelos referidos anticorpos, especialmente quan- do as cepas em teste haviam sido isoladas de pacientes que tiveram dengue hemorrágico ${ }^{(25)}$. Apesar de ser esperado, do ponto de vista probabilístico, que mutações casuais, produtoras de divergências nas sequiências de nucleotídios e de aminoácidos das proteínas de vírus do dengue, causassem infecções com reduzida gravidade, sabe-se que algumas mutações, mesmo únicas, na proteína E de Flavivirus são, provavelmente, responsáveis por aumentar a virulência da cepa viral, particularmente quando localizadas na face distal da região III da proteína $\mathrm{E}$, na base da região II ou na junção entre as regiões I e II ${ }^{(26 / 29)}$. Essas alterações na proteína E melhorariam a capacidade de ligação viral à superfície celular ou dificultariam a ação de anticorpos neutralizantes ${ }^{(30)}$. Sabe-se que as mutações ocorrem a partir de um progenitor comum, aleatóriamente, ao longo do tempo, em conseqüência das complexas interações entre os vírus do dengue e seus dois hospedeiros, o homem e os mosquitos, ambos necessários à manutenção desses vírus na natureza ${ }^{(31)}$. Assim, numa epidemia, devem circular muitas e diferentes variantes virais, estando entre elas os vírus mutantes que tiveram mais sucesso para replicarem nos hospedeiros e serem transmitidos ${ }^{(24)}$. Entretanto, não foram descritas até o momento mutações específicas claramente associadas a quadros de DHF/DSS.

Portanto, o DHF/DSS tem como base fisiopatológica uma resposta imune anômala, desencadeada pela resposta imune do indivíduo infectado e provocada pela cepa viral infectante, envolvendo leucócitos, citocinas e imunocomplexos, causando aumento da permeabilidade por má função vascular endotelial, sem destruição do endotélio, com extravasamento de líquidos para o interstício, causando queda da pressão arterial e manifestações hemorrágicas, associadas a trombocitopenia ${ }^{(1,24)}$. Conseqüentes a tais manifestações, surgem hemoconcentração com redução da volemia, má perfusão tissular, hipóxia e acidose lática. Em autópsias de casos como esses, observamse hemorragias cutâneas, em trato gastrintestinal, no septo interventricular cardíaco, no pericárdio, em espaços subaracnóideos e superfícies viscerais. Também, a hepatomegalia e derrames cavitários são achados comuns ${ }^{(32,33,34)}$. Os derrames em cavidade abdominal e espaço pleural possuem alto teor protéico, com predomínio de albumina e contêm pouco material hemorrágico $^{(32,33,34)}$. Nas análises microscópicas de materiais de necropsia, observa-se edema perivascular com grande extravasamento de hemácias e infiltrado rico em monócitos e linfócitos. Entretanto, não pare- 
ce haver dano de paredes vasculares. Em alguns pacientes adultos, com hemorragias, observam-se abundantes megacariócitos em capilares pulmonares, glomérulos renais, sinusóides hepáticos e esplênicos. São evidências de coagulação intravascular. Em linfonodos e baço, há proliferação linfoplasmocitária com grande atividade celular e necrose de centros germinativos. Reduz-se a polpa branca esplênica e, ali, observa-se linfocitólise abundante com fagocitose daquelas células. Na medula óssea, ocorre bloqueio da maturação megacariocítica e de outras linhagens celulares. No fígado, observa-se hiperplasia, necrose hialina de células de Kuppfer e a presença, em sinusóides, de células mononucleares com citoplasma acidófilo e vacuolizado, semelhantes a corpúsculos de Councilman, lembrando aspecto encontrado na febre amarela. Os hepatócitos apresentam graus variáveis de esteatose e necrose mediozonal. Os rins têm glomerulonefrite relacionada, provavelmente, à deposição de imunocomplexos em membrana basal glome-

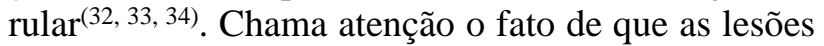
patológicas, observadas, excetuando-se as relacionadas a hemorragias profusas, não justificam a extrema gravidade e o óbito em tais casos de DHF/DSS ${ }^{(32,34)}$.

FIGUEIREDO LTM. Pathogenesis of dengue virus infections. Medicina, Ribeirão Preto, 32: 15-20, jan./march 1999.

ABSTRACT: Aspects of the primary and the secondary infections by dengue viruses are analyzed in this revision article. Two kinds of answers of the immune system to dengue virus infections are described. One of them is beneficial to the patient and impedes further viral reinfections, the other immune answer induces the antibody dependent enhancement of dengue virus infection in macrophages which is important for starting the physiopathologic mechanism of the dengue hemorrhagic. The dengue hemorrhagic is consequence of an anomalous answer of the immune system involving leukocytes, cytokynes and immunocomplexes, causing increase of the vascular permeability without endothelial cell destruction. The increased vascular permeability induces leaking of liquids from the intravascular to the tissue intersticium, causing fall of the blood arterial pressure and hemorrhagic symptoms associated to trombocytopenia.

UNITERMS: Dengue; physiopathology. Dengue Vírus.

\section{REFERÊNCIAS BIBLIOGRÁFICAS}

1 - MONATH TP. Pathology of the Flaviviruses. In: SCHLESINGER $S$ \& SCHLESINGER M, eds. The Togaviridae and Flaviviridae, Plenum Press, New York, p. 375-424, 1986.

2 - KURANE I \& EENNIS FE. Immunity and immunopathology in dengue virus infections. Semin Immunol 4:121-127, 1992.

3 - MONATH TP \& HEINZ F. Flaviviruses. In: FIELDS BN; KNIPE DM \& HOWLEY PM, eds. Virology, Lippincott - Raven, Philadelphia, p.961-1034, 1996.

4 - ALLISON SL et al. Oligomeric rearrangement of tick-borne encephalitis virus envelope proteins induced by na acidic $\mathrm{pH}$. J Virol 69: 695-700, 1995.

5 - CHAMBERS TJ et al.Flavivirus Genome Organization, Expression, and Replication. Annu Rev Microbiol 44: 649-688, 1990.

6 - CHAMBERS TJ et al. Vaccine development against dengue and Japanese encephalitis: report of a World Health Organization meeting. Vaccine 15: 1494-1502, 1997.

7 - FEIGHNY R et al. Purification of native dengue-2 viral proteins and ability of purified proteins to protect mice. Am J Trop Med Hyg 47: 405-412, 1992.
8 - BARBOSA ML. Dengue: Revisão. Rev Inst Adolfo Lutz 56: 27-45, 1996.

9 - FIGUEIREDO LTM et al. Study on an enzyme immunoassay for dengue $\lg G$ and $\lg M$ antibodies detection using infected mosquito cells as antigen. Trans R Acad Trop Med Hyg 83: 702-707, 1989.

10 - RUSSELL PK. Immunophatologic mechanisms in the dengue shock syndrome. In: AMOS B, ed. Progress in immunology, Academic Press, New York, p. 831-838, 1971.

11 - MONATH TP \& TSAI TF. Flaviviruses. In: RICHMAN DD; WHITLEY RJ \& HAYDEN FG, eds. Clinical virology, Churchill Livingstone, New York, p. 1113-1185, 1997.

12 - SANGKAWIBHA N et al. Risk factors in Dengue shock syndrome: a prospective epidemiologic study in Rayong, Thailand. Am J Epidemiol 120: 653-669, 1984.

13 - KOURI GP et al. Hemorrhagic Dengue in Cuba: history of an epidemic. Bull Pan Am Health Organ 20: 24-30, 1986.

14 - THEIN S et al. Risk factors in dengue shock syndrome. Am J Trop Med Hyg 56: 566-572, 1997.

15 - NOGUEIRA RMR et al. Dengue haemorrhagic fever/dengue shock syndrome (DHF/DSS) caused by serotype 2 in Brazil. Mem Inst Oswaldo Cruz 86: 269, 1991. 
16 - ZAGNE SMO et al. Dengue haemorrhagic fever in the State of Rio de Janeiro, Brazil: a study of 56 confirmed cases. Trans R Soc Trop Med Hyg 88: 677-679, 1994.

17 - VASCONCELOS PFC et al. A large epidemic of dengue fever with dengue hemorrhagic cases in Ceará State, Brazil. Rev Inst Med Trop São Paulo 37: 253-255, 1995.

18 - HALSTEAD SB et al. Dengue viruses and mononuclear phagocytes I. Infection enhancement by non- neutralizing antibody. J Exp Med 46: 201-217, 1977.

19 - KLIKS SC et al. Evidence that maternal dengue antibodies are important in the development of dengue hemorrhagic fever in infants. Am J Trop Med Hyg 38: 411-419, 1988.

20 - ROTHMAN Al et al. Molecular basis of immunophathogenesis of dengue hemorrhagic fever. Summaries of the First Dengue in Rio, Rio de Janeiro, p. A19, 1996.

21 - HOBER D et al. Serum levels of tumor necrosis factor- $\alpha$ (TNF- $\alpha$ ), interleukin-6 (IL-6), and interleukin-1b (IL-1b) in dengue infected patients. Am J Trop Med Hyg 48: 324-331, 1993.

22 - YANG KD et al. Production of Cytokines and platelet activating factor in secondary dengue virus infections. J Infect Dis 172: 604, 1995.

23 - KURANE I et al. Dengue virus-specific human CD4'D cytotoxic T-cell clones: Multiple patterns of virus cross reactivity recognize by NS3-specific T cell clones. J Virol 65: 18231928, 1991.

24 - RICO-HESSE R et al. Molecular evolution of dengue type 2 virus in Thailand. Am J Trop Med Hyg 58: 96-101, 1998.

25 - MORENS DM \& HALSTEAD SB. Disease severity related antigenic differences in dengue 2 strains detected by dengue 4 monoclonal antibodies. J Med Virol 22: 169-174, 1987.
26 - REY FA et al. The envelope glycoprotein from tick-borne encephalitis virus at 2 A resolution. Nature 375: 291-298, 1995.

27 - THANT KZ et al. Sequences of E/NS1 gene function from four dengue-2 viruses of Northeastern Thailand and their evolutionary relationships with other dengue-2 viruses. Microbiol Immunol 39: 581-590, 1995.

28 - SITTISOMUT $\mathrm{N}$ et al. Possible occurrence of a genetic bottleneck in dengue serotype 2 viruses between the 1980 and 1987 epidemic seasons in Bangkok, Thailand. Am J Trop Med Hyg 57: 100-108, 1997.

29 - ILKAL MA et al. Entomological investigations during outbreaks of dengue fever in certain villages in Maharashtra State. Indian J Med Res 93: 174-178, 1991.

30 - CHEN LK et al. Generation and characterization of organ-tropism mutants of Japanese encephalitis virus in vivo and in vitro. Virology 223: 79-88, 1996.

31 - WOODRING JL et al. Natural cycles of vector-borne pathogens. In: BEATY BJ \& MARQUARDT WC, eds. The biology of disease vectors, University Press of Colorado, p.5172, 1996.

32 - BHAMAPRAVATI N et al. Pathology of Thailand haemorrhagic fever: study of 100 autopsy cases. Ann Trop Med Parasitol 61: 500-510, 1967.

33 - WORLD HEALTH ORGANIZATION. Dengue haemorrhagic fever: diagnosis, treatment and control, WHO, Geneva, 1986.

34 - FIGUEIREDO LTM \& FONSECA BAL. Dengue. In: VERONESI R \& FOCCACIA R, eds. Tratado de infectologia, Atheneu, São Paulo, p.201-214, 1996.

Recebido para publicação em 23/02/99

Aprovado para publicação em 09/03/99 